\title{
Effects of COVID-19 Pandemic on Turkish Private Practice Dentists' Economic Well-Being
}

\begin{abstract}
SUMMARY
Background/Aim: Coronavirus disease 2019 (COVID-19) is a global health concern. The COVID-19 pandemic has not only health implications but also important social, economic, and political consequences. Dental practices have currently cancelled elective procedures and restricted services to the provision of emergency dental care in order to prevent transmission of COVID-19, which has had serious financial implications. Although several reports about the economic consequences of the COVID19 pandemic have been prepared, no study has analyzed the potential impact of a pandemic on the economy of private-practice dentists. In this context, the purpose of this study is to determine how the COVID-19 has shaped the economic behavior of Turkish private-practice dentists and study the underlying mechanisms. Material and Method: A total of 312 private practice dentists were included in the study. The researchers developed a closed-ended questionnaire that contained 10 questions and was divided into three parts. The first part captured demographic information (age, gender, and professional experience of dentists). The second part measured the economic effects of the pandemic. The third part explored the dentists' economic behavior in the post-pandemic period. Results: Over half (52.6\%) of the dentists stated that during the pandemic, they only cared for patients in emergency situations. Most (97.4\%) of the dentists stated that the pandemic affected their economic situation negatively, and $66.7 \%$ of dentists stated that they could not meet their routine clinical expenses during the pandemic. In the post-pandemic period, 52.6\% of dentists are considering increasing their treatment fees, and 19.2\% of dentists are considering dismissing some of their employees for economic reasons. Conclusions: The significant limitation of clinical and surgical activities in private dental practice caused by the COVID-19 pandemic has had a very significant negative effect on private-practice dentists' economic well-being.
\end{abstract}

Key words: COVID-19, Dentists, Economics, Pandemics
Fatih Karaaslan, Ahu Dikilitaș, Umut Yiğit

Department of Periodontology, Faculty of Dentistry, Usak University, Usak, Turkey

ORIGINAL PAPER (OP)

Balk J Dent Med, 2021;178-182

\section{Introduction}

The coronavirus disease 2019 (COVID-19) is a global health concern. The World Health Organization declared the COVID-19 outbreak $^{1}$ to be a global pandemic on March 11, 2020. The clinical presentation of COVID-19 ranges from a common cold to severe pneumonia with acute respiratory distress syndrome, which may result in death. COVID-19 spreads from person to person through respiratory droplets generated when an infected person coughs or sneezes. Contact with contaminated surfaces and inhalation of aerosols produced during aerosol-generating procedures are other routes of COVID-19 transmission ${ }^{2,3}$. Wearing face masks, reducing contact rates, and following social distance measures are recommended precautionary behaviors ${ }^{4}$.

Today, the COVID-19 pandemic has not only health implications but also important social, economic, and political consequences ${ }^{5}$. The economic outcomes of 
COVID-19 include the disruption of a large spectrum of workforce sectors ${ }^{6}$. Dental practices have currently cancelled elective procedures and restricted services to the provision of emergency dental care in order to prevent COVID-19 transmission, creating serious financial implications ${ }^{7}$. The uncertainty of the pandemic and the associated economic losses make it difficult for dentists to maintain financial continuity ${ }^{8}$.

Identifying the financial difficulties that dentistry practices face in ensuring the efficient provision of all types of oral healthcare can contribute to preventing greater economic effects ${ }^{9}$. Although several reports about the economic consequences of the COVID-19 pandemic have been created, no study has analyzed the potential impact of a pandemic on the economy of private-practice dentists $^{10-12}$. In this context, the purpose of this study is to determine how the COVID-19 pandemic has shaped dentists' economic behavior and study underlying mechanisms.

\section{Material and Methods}

This study was carried out at Usak University Faculty of Dentistry. A total of 312 private-practice dentists were included in the study. The study was conducted according to the Helsinki Declaration, and ethical permission was obtained from the local ethics committee of Usak University.

\section{Questionnaire}

The researchers developed a closed-ended questionnaire that contained 10 questions and was divided into three parts. The first part captured demographic information (age, gender, and professional experience of dentists). The second part measured the economic effects of the pandemic. The third part explored dentists' economic behavior in the post-pandemic period. The data was collected by sending an online link to dentists to minimize the risk of COVID-19 transmission.

\section{Sample size calculation}

The sample size was determined using the $\mathrm{G}^{*}$ Power 3.1 program. Type 1 error $(\alpha)=0.05$, effect size $=0.50$, and test power $(1-\beta)=0.80$ were calculated. The sample size was determined to be a minimum of 238 dentists.

\section{Statistical analyses}

Data analysis was performed using the software Statistical Package version 17.0 (SPSS Inc., Chicago, IL, USA), and the statistical significance level was set at 0.05 . Test-retest reliability of the questionnaire was assessed by calculating intraclass correlation coefficients, and Cronbach's alpha was used to ascertain the internal consistency of the questionnaire. Demographic information and the economic effects of the pandemic were evaluated using descriptive statistical analysis.

\section{Internal and external reliability of questionnaire}

External reliability (test-retest reliability) was determined by calculating the measurement error in the repeated answers of the questionnaire given to 32 dentists twice within a one-week period. Test-retest reliability was found to be positive, high, and statistically significant $(\mathrm{r}=0.826 ; \mathrm{p}<0.01)$. The internal reliability of the questionnaire was measured using Cronbach's alpha. The Cronbach's alpha value was 0.738 , which indicates acceptable internal consistency.

\section{Results}

A total of 312 dentists, 108 (34.6\%) females and 204 $(65.4 \%)$ males, participated in the study. Of these, $65.4 \%$ have been private-practice dentists for more than 10 years. Age, gender, and years of professional experience as dentists are given in Table 1.

Table 1. Age, gender and professional experience of dentists

\begin{tabular}{lccc}
\hline Demographic data & & $\mathrm{n}$ & $\%$ \\
\hline \multirow{2}{*}{ Gender } & Female & 108 & 34.6 \\
& Male & 204 & 65.4 \\
\hline \multirow{3}{*}{ Age group } & $24-34$ & 112 & 35.9 \\
& $35-44$ & 88 & 28.2 \\
& $45-54$ & 96 & 30.8 \\
& $55-64$ & 16 & 5.1 \\
\hline \multirow{3}{*}{ Years of professional experience } & $11-20$ year & 108 & 34.6 \\
as dentist & $21-30$ year & 76 & 24.4 \\
& $31-40$ year & 20 & 6.4 \\
\hline
\end{tabular}

Of the dentists, $16.7 \%$ stated that they did not take care of any patients during the pandemic, and $52.6 \%$ stated that they only looked after the patients in emergency situations. Nearly all (97.4\%) of the dentists stated that the pandemic affected their economic situation negatively, and $66.7 \%$ of dentists stated that they could not meet their routine clinical expenses during the pandemic. Moreover, $85.9 \%$ of dentists stated that they were unable to get necessary support and help from state institutions (Table 2). 
Table 2. Economic effects of pandemic

\begin{tabular}{|c|c|c|c|c|c|c|c|}
\hline \multirow{3}{*}{ Questions } & \multirow{3}{*}{ Answers } & \multicolumn{6}{|c|}{ Dentists } \\
\hline & & \multicolumn{2}{|c|}{ Female } & \multicolumn{2}{|c|}{ Male } & \multicolumn{2}{|c|}{ Total } \\
\hline & & $\mathrm{n}$ & $\%$ & $\mathrm{n}$ & $\%$ & $\mathrm{n}$ & $\%$ \\
\hline \multirow{5}{*}{$\begin{array}{l}\text { How often did you give dental } \\
\text { treatment during pandemic }\end{array}$} & I didn't spoil my routine (every day) & 4 & 33.3 & 8 & 66.7 & 12 & 3.8 \\
\hline & Once every three or four days & 11 & 30.5 & 25 & 69.5 & 36 & 11.5 \\
\hline & Once a week & 13 & 27.1 & 35 & 72.9 & 48 & 15.4 \\
\hline & Only emergency & 57 & 34.7 & 107 & 65.3 & 164 & 52.6 \\
\hline & Never & 23 & 44.2 & 29 & 55.8 & 52 & 16.7 \\
\hline \multirow{2}{*}{$\begin{array}{l}\text { How COVID- } 19 \text { pandemic has } \\
\text { affected you economically }\end{array}$} & Negatively affected & 103 & 33.8 & 201 & 66.2 & 304 & 97.4 \\
\hline & Not affected & 5 & 62.5 & 3 & 37.5 & 8 & 2.6 \\
\hline \multirow{3}{*}{$\begin{array}{l}\text { Can you afford your routine clinical } \\
\text { expenses during pandemic }\end{array}$} & Yes & 33 & 48.5 & 35 & 51.5 & 68 & 21.8 \\
\hline & No & 59 & 28.3 & 149 & 71.7 & 208 & 66.7 \\
\hline & No idea & 16 & 44.4 & 20 & 55.6 & 36 & 11.5 \\
\hline \multirow{3}{*}{$\begin{array}{l}\text { Do you think that you have received } \\
\text { the necessary support and assistance } \\
\text { from goverment institutions during } \\
\text { the pandemic? }\end{array}$} & Yes & 19 & 52.7 & 17 & 47.3 & 36 & 11.5 \\
\hline & No & 84 & 31.3 & 184 & 68.7 & 268 & 85.9 \\
\hline & No idea & 5 & 62.5 & 3 & 37.5 & 8 & 2.6 \\
\hline
\end{tabular}

Table 3. Economic behavior options of dentists in the post-pandemic period

\begin{tabular}{|c|c|c|c|c|c|c|c|}
\hline \multirow{3}{*}{ Questions } & \multirow{3}{*}{ Answers } & \multicolumn{6}{|c|}{ Dentists } \\
\hline & & \multicolumn{2}{|c|}{ Female } & \multicolumn{2}{|c|}{ Male } & \multicolumn{2}{|c|}{ Total } \\
\hline & & $\mathrm{n}$ & $\%$ & $\mathrm{n}$ & $\%$ & $\mathrm{n}$ & $\%$ \\
\hline \multirow{3}{*}{$\begin{array}{l}\text { Do you think to increase the } \\
\text { treatment fees in the post- } \\
\text { pandemic period? }\end{array}$} & Yes & 64 & 39.1 & 100 & 60.9 & 164 & 52.6 \\
\hline & No & 23 & 30.2 & 53 & 69.8 & 76 & 24.4 \\
\hline & No idea & 21 & 29.1 & 51 & 70.9 & 72 & 23.0 \\
\hline \multirow{3}{*}{$\begin{array}{l}\text { Do you think of firing your } \\
\text { employees due to economic } \\
\text { reasons after the pandemic? }\end{array}$} & Yes & 21 & 35.0 & 39 & 65.0 & 60 & 19.3 \\
\hline & No & 64 & 32.6 & 132 & 67.4 & 196 & 62.8 \\
\hline & No idea & 23 & 41.1 & 33 & 58.9 & 56 & 17.9 \\
\hline \multirow{3}{*}{$\begin{array}{l}\text { Do you consider investing in } \\
\text { your clinics infection control } \\
\text { equipments after pandemic }\end{array}$} & Yes & 74 & 33.1 & 150 & 66.9 & 224 & 71.8 \\
\hline & No & 23 & 35.9 & 41 & 64.1 & 64 & 20.5 \\
\hline & No idea & 11 & 45.8 & 13 & 54.2 & 24 & 7.7 \\
\hline
\end{tabular}

In the post-pandemic period, $52.6 \%$ of dentists are considering increasing treatment fees, $19.2 \%$ of dentists are considering dismissing some of their employees for economic reasons, and $71.8 \%$ of dentists are considering investing in their clinic's infection control equipment (Table 3).

\section{Discussion}

The COVID-19 pandemic not only poses a global threat to human health but also has economic effects ${ }^{13}$. It was reported that millions of jobs will be lost and the unemployment rate will rise because of economic crisis COVID-19 has caused ${ }^{11}$. Many sectors will be dealing with the economic fallout of the pandemic for years. However, each sector is responding differently in overcoming the negative economic situation caused by the pandemic ${ }^{14}$. In this context, this paper presents the financial impact of the COVID-19 pandemic on the dental sector in Turkey.

More than half of the dentists surveyed stated that they have been providing only emergency dental treatments, and nearly one-fifth of dentists have closed their practices temporarily during the pandemic period. The main reason for this restriction in routine dentistry practice is that many dental treatment procedures produce aerosol and droplets that contain a mixture of water and the patient's blood and saliva ${ }^{7,15,16}$. These aerosols could spread the COVID-19 infection, and the risk of crosscontamination can be high between dentists and patients. National and international health regulatory bodies have also advised dentists to postpone all elective treatments and only intervene in emergencies ${ }^{17}$.

Almost all dentists stated that the pandemic has negatively affected their economic situations. The uncertainty and economic losses associated 
with the pandemic have caused high volatility and unpredictable consequences as dentists consider the financial implications of continuing their jobs. The most important cause of serious monetary losses for dentists is the inability to perform optional treatments, such as restorative, prosthetic, and dental implant applications, which constitute the majority of dental procedures and improve patients' quality of life $^{18}$. Another cause is that individuals have been advised to stay at home except for life-threatening emergencies ${ }^{19}$. In accordance with these findings, it is also reported that dental practices all around the world are suffering huge financial losses, as they can provide only emergency dental care ${ }^{20}$.

Indeed, $66.7 \%$ of the dentists stated that they could not afford their routine clinical expenses and employee salaries during the pandemic period. Although the dentists have reduced their employees' working hours, they have not cut their salaries or reduced expenses such as rent. In other words, while expenses remain constant, the decrease in revenue endangers the economic continuity of dentists. This finding reveals the need for dentists to be supported by well-targeted policies to remove the economic bottleneck caused by the pandemic ${ }^{20}$.

About $85 \%$ of dentists stated that they were unable to receive necessary support from government institutions during the pandemic. Although it has started to provide a large package of economic support, including wage subsidies for government citizens and businesses, cash transfers to low-income households and tax breaks for businesses, and short employment allowances for those who are unable to work due to the pandemic to prevent major layoffs, there has been no financial support for private-practice dentists in Turkey ${ }^{21,22}$. The governments and dental regulatory bodies of many high-income countries have supported dental practices, but the Turkish government has put forth no visible policy to support dental practices ${ }^{8}$.

Dentists' main priority will be safety so that they can protect their economic situations and maintain business operations in the post-pandemic world. Dentists are considering adaptation behaviors to reduce the impact of disease ${ }^{23}$. Approximately half of the dentists are considering increasing treatment fees in the postpandemic period to compensate for economic losses during the pandemic, minimize the cost of disease avoidance, and ensure economic viability. About onefifth of dentists are considering dismissing at least one employee after the pandemic, indicating that unemployment will increase and economic recovery will take longer. Also, $70 \%$ of dentists are considering investing in preventive measures in their clinics to prevent the transmission and spread of COVID-19 infection. It is crucial for dentists to refine preventive strategies to avoid COVID-19 infection in the post-pandemic period and to be able to provide routine clinical procedures in addition to emergency treatments ${ }^{16,24}$.
There are some limitations. First, this study does not include all dentists in the country, and large studies are needed to allow more dentists to participate. Second, only the short-term behavior of dentists is examined, and further research is needed to examine their medium- and long-term economic behaviors.

\section{Conclusions}

Employment, social, and economic factors associated with the pandemic have affected dentists. Private-practice dentists face significant uncertainty in the wake of COVID-19, which is impacting the incomes of private practices, and many are in desperate financial circumstances. The significant restriction of clinical and surgical activities in dental practice caused by the COVID-19 pandemic has had very impactful negative effects on private-practice dentists' economic well-being.

\section{References}

1. World Health Organization. Novel coronavirus (2019$\mathrm{nCoV}$ ) situation report-51. https:/www.who.int/docs/ default-source/coronaviruse/situation-reports/20200311sitrep-51-covid-19.pdf?sfvrsn=1ba62e57_10. March 11, 2020.

2. Lai CC, Shih TP, Ko WC, Tang HJ, Hsueh PR. Severe acute respiratory syndrome coronavirus 2 (SARS-CoV-2) and coronavirus disease-2019 (COVID-19): The epidemic and the challenges. Int J Antimicrob Agents, 2020;55:1-9.

3. Guo G, Ye L, Pan K, Chen Y, Xing D, Yan K, et al. New Insights of Emerging SARS-CoV-2: Epidemiology, Etiology, Clinical Features, Clinical Treatment, and Prevention. Front Cell Dev Biol, 2020;8:410:1-22.

4. Chu DK, Akl EA, Duda S, Solo K, Yaacoub S, Schünemann HJ. Physical distancing, face masks, and eye protection to prevent person-to-person transmission of SARS-CoV-2 and COVID-19: a systematic review and meta-analysis. Lancet, 2020;6736: 31142-31149.

5. Nicola M, Alsafi Z, Sohrabi C, Kerwan A, Al-Jabir A, Iosifidis $\mathrm{C}$, et al. The socio-economic implications of the coronavirus and COVID-19 pandemic: a review. Int J Surg, 2020;78:185-193.

6. Guerrieri V, Lorenzoni G, Straub L, Werning I. Macroeconomic Implications of COVID-19: Can Negative Supply Shocks Cause Demand Shortages? Report no. 0898-2937, 2020. National Bureau of Economic Research. Massachusetts, Cambridge, USA. April 2020.

7. Ather A, Patel B, Ruparel NB, Diogenes A, Hargreaves KM. Coronavirus disease 19 (COVID-19): implications for clinical dental care. J Endod, 2020;46:584-595.

8. Coulthard P. Dentistry and coronavirus (COVID-19)-moral decision-making. Br Dent J, 2020;228:503-505. 
9. Adams JG, Walls RM. Supporting the health care workforce during the COVID-19 global epidemic. Jama 2020; 323: 1439-40.

10. McKibbin WJ, Fernando R. The global macroeconomic impacts of COVID-19: Seven scenarios. Cama, 2020;19:143.

11. McKibbin W, Fernando R. The economic impact of COVID-19. In: Baldwin R, di Mauro BW. Economics in the Time of COVID-19. CEPR Press, 2020;3:45-53.

12. Cavallo JJ, Forman HP. The economic impact of the COVID-19 pandemic on radiology practices. Radiol, 2020;201495:1-13.

13. McKee M, Stuckler D. If the world fails to protect the economy, COVID-19 will damage health not just now but also in the future. Nat Med, 2020;26:640-642.

14. Béland LP, Brodeur A, Wright T. The short-term economic consequences of Covid-19: exposure to disease, remote work and government response. IZA Disussion Paper No 13159, 2020;1-90.

15. Spagnuolo G, De Vito D, Rengo S, Tatullo M. COVID-19 outbreak: An overview on dentistry. Int J Enviro Res Public Health, 2020;17:2094-2097.

16. Ge ZY, Yang LM, Xia JJ, Fu XH, Zhang YZ. Possible aerosol transmission of COVID-19 and special precautions in dentistry. J Zhejiang Univ Sci B, 2020;21:361-368.

17. Pereira LJ, Pereira CV, Murata RM, Pardi V, PereiraDourado SM. Biological and social aspects of Coronavirus Disease 2019 (COVID-19) related to oral health. Braz Oral Res, 2020;34:1-11.

18. Abramovitz I, Palmon A, Levy D, Karabucak B, Kot-Limon $\mathrm{N}$, Shay B, et al. Dental care during the coronavirus disease 2019 (COVID-19) outbreak: operatory considerations and clinical aspects. Quintessence Int, 2020;51:418-429.

19. Gostin LO, Wiley LF. Governmental public health powers during the COVID-19 pandemic: stay-at-home orders, business closures, and travel restrictions. Jama, 2020;323:2137-2138.
20. Farooq I, Ali S. COVID-19 outbreak and its monetary implications for dental practices, hospitals and healthcare workers. Postgrad Med J, 2020;96:791-792.

21. Açikgöz Ö and Günay A. The early impact of the Covid-19 pandemic on the global and Turkish economy. Turk J Med Sci, 2020;50:520-526.

22. Bostan S, Erdem R, Öztürk YE, Kılıç T, Yılmaz A. The Effect of COVID-19 Pandemic on the Turkish Society. Electron J Gen Med, 2020;17:1-8.

23. Ahmed MA, Jouhar R, Ahmed N, Adnan S, Aftab M, Zafar MS, et al. Fear and practice modifications among dentists to combat Novel Coronavirus Disease (COVID-19) outbreak. Int J Environ Res Public Health, 2020;17:1-12.

24. Khader Y, Al Nsour M, Al-Batayneh OB, Saadeh R, Bashier $\mathrm{H}$, Alfagih M, et al. Dentists' awareness, perception, and attitude regarding COVID-19 and infection control: crosssectional study among Jordanian dentists. JMIR Public Health Surveill, 2020;6:18798.

Conflict of Interests: Nothing to declare.

Financial Disclosure Statement: Nothing to declare.

Human Rights Statement: All the procedures on humans were conducted in accordance with the Helsinki Declaration of 1975, as revised 2000. Consent was obtained from the patient/s and approved for the current study by national ethical committee.

Animal Rights Statement: None required.

Received on September 16, 2020.

Revised on November 10, 2021.

Accepted on May 20, 2021.

\section{Correspondence:}

Fatih Karaaslan

Department of Periodontology

Faculty of Dentistry, Usak University, Usak, Turkey

e-mail: fatih.karaaslan@usak.edu.tr 